\title{
The Phenomenon of Information in the Modern World: A Philosophical Approach
}

This article acknowledges that today, the scientific theory of information remains unclear. However, in the modern world, which is undergoing the transition to a new stage of development, that is, a postindustrial society (Industry 4.0), the phenomenon of information becomes a fundamental category of scientific knowledge and a constitutive feature of a new stage of development. In the context of the latest scientific concepts and experiments, from the philosophical point of view, information can be considered as "some initially assigned givenness" (Nalimov, 1989, p. 229). This approach allows us to assume that it is not information that is the way and means to acquire knowledge, as many researchers believe, but knowledge is the way and means to obtain information which is a fundamental essence of the reality.

Almost all serious researchers note that the modern global megasociety is undergoing the transition to a qualitatively different state, which cannot be described with today's universals of the worldview (of a human, world, global evolution of a human, world, society) (Letov, 2009). Different researchers name this qualitatively different state of the society variously: post-industrial society, post-capitalist society, post-economic society, super-industrial society, information society, the society of knowledge, etc.

Since the 1960s, the theory of 'post-industrial society' has become the methodological paradigm in social science research on this "different" state of society. The theory of the post-industrial society by Daniel Bell rightfully takes a central place among these theories, since it [the theory] is a theoretical abstraction which allows comprehending the most important trends in the development of the management and the structure of the productive forces, science, and education of advanced Western countries.

In the analytical concept of Bell's 'post-industrial society', social changes are presented as a multidimensional process. In this process, the importance of the information sector increases, compared to the production of goods; the role of the information component in production processes is enhanced (compared to raw materials and energy); and social guidelines are revised. Production and exploitation of information and knowledge are the characteristics of the post- 
Raushan Sartayeva, Natalya Seytakhmetova, Galiya Kurmangaliyeva, Gulzhikhan Nurysheva, Sholpan Zhandosova

industrial society. As many researchers believe, this allows "in economic and social planning, to move from instinctive judgments to the algorithms based on computer processing of information and to ensure full scientification of all areas of life" (Bechmann, 2010). That is, theoretical knowledge becomes the leading principle of social organization, and the post-industrial society is moving towards the information society or the knowledge society. Therefore, many researchers began to call the new post-industrial society the information society. It reflects the desire to identify production and exploitation of information and knowledge as the main characteristic of this society. In the scientific community, the concept of 'information society' was introduced by Fritz Machlup (USA) and Tadao Umesao (Japan). Such famous scientists as Yoneji Masuda, Marc Porat, Raul Katz, Tom Stonier and many others have contributed to the further development of the concept of information society.

As a result of the radical change in the modern cultural and civilization system, a new socio-cultural reality is emerging. Processes of globalization occur in a certain sociocultural space, which is a unity of social and cultural components. This means that the changes occurring in the modern sociocultural space involve both society and culture. The transition of modern society to the information society has caused a number of profound transformations in the cultural domain, which is a dynamically developing informational and communicative space today.

Information (together with knowledge) is becoming the most powerful resource in the development of the modern society. Moreover, in the light of the latest scientific research, information is a fundamental category in the context of modern scientific knowledge in general.

The stage of development of the modern civilization is characterized by the flow (in the context of new communication technologies) of huge amounts of information into the sociocultural space. The phenomenon of information (together with the phenomenon of knowledge) becomes a constitutive feature of the new post-industrial stage in the development of the global megasociety.

Accordingly, philosophical thought of the phenomenon of information, as opposed to understanding information only as a concept of cybernetics, becomes a necessity.

Different approaches to understanding the phenomenon of information, their diversity, attest to the excellent heuristic potential of this phenomenon, 
which provides new methodological opportunities in understanding universal connections, in understanding the integrity of the reality surrounding us.

The ontological status of the information phenomenon is determined by the connection with fundamental philosophical subject matters and modern civilization development challenges in general: the principle of integrity, universal connections, the relationship between animate and inanimate nature, the problem of the relationship between being and thinking, the identity of morality and thought, issues of communication, cybernetics, robotics, artificial intelligence, virtual reality, etc.

As is known, the foundation of the information theory was the article 'Mathematical theory of communication' published in 1948 by Claude Shannon (1948) and Norbert Wiener's (1948) book on cybernetics. Since then, many researchers have believed that "the concept of information has become the central concept of the century" (Garai, 2019, p. 118). To the point, information as a general scientific category that has interdisciplinary significance was first considered not only in Claude Shannon's (1963) papers but also in those of Ralph Hartley (1959), devoted to the issues of engineering communications and relation. In addition, Claude Shannon considered information from the standpoint of the entropy of material systems (1963).

Furthermore, physicist Léon Brillouin (1956) created a special theory of information in which he associated information with the physical concept of matter.

The above works, the subsequent barrage of research in this field and the peculiarities of the development of the global megasociety in the direction of the so-called information society have created an acute need for serious philosophical thought on the phenomenon of information.

Today, all researchers involved in the research of the phenomenon of information agree that information is the most important asset of the material world. Nevertheless, there are different approaches to dealing with this phenomenon, the most important of which, according to most researchers, are attributive and functional approaches. Some researchers believe that there are also such approaches as structural, synergistic, substrate. And they add, say, a substrate approach in content and significance to the above main ones, considering the substrate approach to be the quintessence of attributive, functional, synergetic and structural approaches (Bakayeva, 2010). 
Raushan Sartayeva, Natalya Seytakhmetova, Galiya Kurmangaliyeva, Gulzhikhan Nurysheva, Sholpan Zhandosova

As a whole, proponents of both attributive and functional approaches to the phenomenon of information recognize that information is a property of all levels of the material world. However, "functionalists" do not recognize the functionality of information at the level of inanimate nature. Recently, in fact, as many researchers have noted, the intensity of the discussion between the proponents of the two main approaches has somewhat decreased after the appearance of Ilya Prigogine and Hermann Haken's papers on self-organization, which gave a new theoretical justification to the attributive approach and made it possible to present the phenomenon of information as having ontological and logical epistemological statuses (Bogatyryeva, 2000).

Here, the phenomenon of information is considered in terms of its ontological, fundamental status.

In the 1940s (or, more precisely, after 1945), as noted by Peter Ingwersen (1992), there was an interest in information as a phenomenon of public consciousness in academic circles. Ingwersen's article describes the process of the formation of theoretical and applied sciences into a new cluster of information sciences, such as information economics, historical informatics, information technologies, information law, information epistemology, information marketing, etc. (Ingwersen, 1992).

It is believed that the term 'information society' was first proposed by the Japanese scientist Kosuke Koyama, whose works formed the basis of the program 'Plan of the Information Society: National Goal by 2000' (Solovyev, 2001, p. 142). Moreover, the work of another Japanese researcher Yoneji Masuda Information Society as an Industrial Society (Masuda, 1981) contributed to the approval and dissemination of this term. There is also a point of view that the concept of 'information society' was introduced in scientific research by Machlup (1998) and Umesao. As mentioned previously, the studies of such famous scientists as Porat, Katz, Stonier, and many others contributed to the further development of the concept of the information society.

As mentioned previously, such terms as the information society and the knowledge society are used to determine a new stage in the development of the global megasociety. Some researchers have proposed to consider the information society as a prerequisite of the knowledge society (or the society of different knowledge). But most researchers believe that they have a similar meaning within the context of the determination of a new stage of the development of the modern civilization (Kochetkov, 2011). According to the authors of this article, this 
similarity is due to the fact that the phenomena of information and knowledge are historically inextricably linked, and their production and exploitation have become constitutive features of post-industrial societies. According to the authors, in this context, it is unreasonable and, using Heidegger's terminology, logically incoherent to divide the post-industrial stage of the development of the global megasociety into the stage of the information society and the stage of the knowledge society. However, the authors certainly share the concepts of information and knowledge, which are inextricably linked to each other, as mentioned previously.

As a first step in coming closer to a solution for this issue, we can note the relatively close point of view of Yelena N. Bogatyryeva, who claims that

Information and knowledge are mutually related phenomena and their corresponding concepts. If information ontologically is a measure of changes and a measure of relationships in the system of reality, then knowledge is a substantively true and subject-based mastery of information on personal and suprapersonal levels of the subject's functioning. (Bogatyryeva, 2000)

Today, information has become a general scientific concept, and the "informational approach, which includes a set of ideas and a complex of mathematical tools, has become a general scientific means of research" (Ursul, 1983). Also, many researchers emphasize that "general scientific phenomena are a specific type of connection between the generalized philosophical methodology and specific methodologies of special sciences" (Bogatyryeva, 2000). Hence, a conclusion can be made that a philosophical analysis of the phenomenon of information is essential. In this regard, as many researchers note, its ideological, philosophical interpretations have appeared. In the context of philosophical studies, the concepts of information of an objectively idealistic sense (neo-Thomism) were developed; according to these concepts, the phenomenon of information has a supernatural, transcendental essence. Different existentialist and neopositivist concepts consider information as a subjective phenomenon.

Dialectical materialism considered information relying on the thesis that material information preceded ideal information and on its connection with reflection. Previously, according to some philosophical dictionaries and encyclopedias, it was very common to define information based on the category of diversity (W. Ross Ashby) and the category of reflection as a property of all matter (Marxism) (Ursul, 1983). 
Raushan Sartayeva, Natalya Seytakhmetova, Galiya Kurmangaliyeva, Gulzhikhan Nurysheva, Sholpan Zhandosova

Today, the phenomenon of information is usually considered in the context of information theory, which is defined as "a special scientific discipline, usually represented as a section of cybernetics analyzing the mathematical aspects of collecting, transfer, processing, and storage of information" (Smolyan, 2001, p. 141). It is noted that

numerous attempts to consider information as an invariant representation form of an ideal object in relation to types of human activity (knowledge, artistic image, natural or artificial languages, etc.) and to use concepts, principles and the formal apparatus of the theory in broad cultural, linguistic and scientific contexts (Mol, Nalimov, Schreider, and others) did not lead to any significant success (Smolyan, 2001, p. 141).

In particular, it is noted that "it was not possible to build a strict semantic theory of information, as well as to formalize concepts based on the concept of "value" of information" (Smolyan, 2001, p. 142).

Moreover, it is claimed that, today, according to the non-mathematical interpretation, the study of informational interactions is the most important part of the information theory.

The study of informational interactions involves an extensive use of linguistic approaches and procedures [...], as well as axiological, cognitive and psychological approaches and methods to a large number of factors determining the informational interactions between people. (Smolyan, 2001, p. 142)

By the way, the famous Hungarian psychologist Laszlo Garai $(2017 ; 2019)$ noted the interdependence and complementarity of the theory of information (the information approach in the human sciences) and the theory of socio-historical identity. He argued that

two factors are decisive for the use of information in economic life: (a) its production at a location and time set; (b) its use at the correct place and time. The first of these two factors is ensured by substantive activity, while the second factor requires the creation of a sociohistorical identity. (Garai, 2019, p. 118)

In our opinion, today, this approach is very relevant in the context of the increasing challenges associated with the phenomenon of information in the modern world and all types of identities. 
At another point, all these quotations are given by the authors to show that philosophical research is often and actively tied up in the non-philosophical content. At best, such studies can state the manifestation of the so-called 'exegetical turn' (the term of Jaakko Hintikka). According to Hintikka, the famous Finnish philosopher, and logician, "today, the prevailing paradigm of philosophical activity is not scientific research, but exegesis, that is, clarification or interpretation of sacred texts or, perhaps, a creative interpretation of great works of world literature" (Hintikka, 2011, p. 4).

Today, it is clear that the concept of informational interaction is of great interest to a wide range of scientific disciplines, including philosophical studies. But the latter (philosophical studies) should not be carried out to the detriment of the philosophical content, evolving, as it often happens recently, "according to L. Fejer's absolutely fair expression, into useless scholastic exercises or semanticsemiotic narrow sectoral linguistic studies" (Davidovich, 1997, p. 2).

As many researchers note, information was understood as data about something (associated, for example, with control, signals in the unity of syntactic, semantic and pragmatic characteristics, etc.) until the middle of the last century. According to the authors, such an approach, in general, still applies, although there are no entirely coherent attempts to separate the concepts of 'information' and 'data' (Glaser). Thus, it is argued that information can be defined as "data that is organized and structured, that is, placed in context, and, therefore, endowed with meaning" (Bechmann, 2010, pp. 121-122). According to Peter F. Drucker (1969), information is data that has undergone computer processing. Some researchers believe that information "is just one of the special forms of knowledge, namely, the way and means of transporting knowledge" (Mittelstraß) (Bechmann, 2010, p. 122). One may agree with Bechmann, who claims that "information is deeply ambivalent. [...] It contains its opposite, at the same time reproducing both knowledge and ignorance" (Bechmann, 2010, p. 123).

Today, in the context of the so-called integral philosophy (and modern scientific research), which acknowledges a combination (it is clear that it should be logical and provable) of positions which are different in their basis within one concept, the phenomenon of information can be viewed as fundamental in the modern picture of the world, with its transcendental (supernatural), subjective, and material nature. This understanding of information is not just conventional but is the result of the development and achievements of modern science. More than half a century has passed since the cyberneticist Norbert Wiener wrote that "information is information, not matter or energy" (Wiener, 1948), and modern 
Raushan Sartayeva, Natalya Seytakhmetova,

Galiya Kurmangaliyeva, Gulzhikhan Nurysheva,

Sholpan Zhandosova

science presents very significant counter-arguments to this thesis.

As many researchers note, complicated processes occurring in the modern sociocultural reality can be adequately understood only taking into account the characteristics of the new information culture based on new forms of communication (Kasumova, 2011). The special character of the communicative space where modern culture develops in the context of globalization implies that both the meaning of individual units of communication and the whole semantic field are changing. Recently, as a result of the increasing power of constantly updating and improving mass media technologies, the phenomenon of 'overproduction of information' has emerged, and Al Gore, former Vice President of the USA, called it 'exformation'. According to many researchers, 'exformation' has deprived a person of cognitive, social, human communication in its traditional sense. A person not only does not have time to realize and perceive all the new information but also to interpret it logically, semantically. Thus, the meaning of the incoming information is lost; there is a situation of "semantic emptiness" (Kasumova, 2011). That is, in modern conditions, the theoretical-cognitive role of information decreases; information is being transmitted through emotional-imaginative channels, and the emphasis is not on the content, but on the carrier, the image.

Although the well-known Russian cyberneticist R. F. Abdeev, in his book on the philosophy of informational civilization, complained that "information has not yet been recognized as a philosophical category" (Abdeev, 1994, p. 9), today, according to the authors, information is a very important category in philosophy, which allows removing the possible contradiction between the new understanding of the principle of wholeness and the effect of emergence. This contradiction is removed by introducing the concept of information as the essence of the outside world and the substrate as a phenomenon of this essence (Grof, 1985; 1993; Sartayeva, 2012; 2018).

According to the new understanding of the principle of wholeness, the emphasis is shifted from the phenomenon of self-sufficiency, self-determination of an object to its 'external surroundings' (general relations), and a new approach to the problem of the relationship between 'part' and 'whole' is used, (as opposed to the former "conventional" approach based on serious scientific concepts that claim to be the Theory of Everything). These are the theory of superstrings, the theory of holomovement of David Bohm (1981), Arthur Young's theory of processes (Young, 1976), the theory of dissipative structures of Ilya Prigogine and Isabelle Stengers (Prigogine \& Stengers, 2001), and the research of some radical 
schools of thought (Geoffrey Chew's (1968) bootstrap theory, the research of a British physicist Makhoy Miles (see Pudomyagin, 2007), the concept of fractal geometry of nature by Benoit Mandelbrot (Mandelbrot, 1977), and others.

A new understanding of the principle of wholeness emerges on the basis of the so-called holonomic-holographic approach, which plays a big role in the process of modern scientific knowledge. In its turn, the phenomenon of information is the basic concept of a holonomic-holographic approach (Grof, 1985; 1993).

The holonomic-holographic approach based on the principles of the so-called holomovement of the outstanding theoretical physicist David Bohm and the technique of holography, the mathematical principles of which were developed by the British scientist Dennis Gabor (Nobel Laureate of 1971), should be combined with Prigogine's and Stengers' concept of 'order through fluctuations'. This concept, in its turn, should be the basis of modern systematic and structural analysis.

The holonomic-holographic approach contributes to the emergence of a new understanding of the 'whole', 'wholeness', and the relationship between the part and the whole. It allows transcending the difference between the part and the whole, which seems unresolved (Grof, 1985; 1993). The problem of wholeness, the whole, the part and the whole is one of the key problems in philosophy, as it has a deep ontological meaning. Therefore, it can be said that the holonomicholographic approach contributes to the development of new approaches to worldview and conceptual and methodological approaches in philosophy; namely, it allows to combine, reconcile metaphysics and dialectics, materialism and idealism within the framework of the new synthesizing philosophy.

This approach (holonomic-holographic) is based on the following thesis: any tiny part of any system contains information about the entire system. That is, this thesis reflects a new approach to the philosophical problem of the relationship between the part and the whole, in contrast to the former "conventional" approach. Moreover, this understanding of the relationship between the part and the whole does not contradict the phenomenon of emergence, according to which it is confirmed that the systemic whole has the properties that are not inherent in its subsystems and blocks. In overcoming the antinomy of the abovementioned situation, the concepts of the substrate and information play an important role within the framework of the holonomic-holographic approach. The information is shown as an essence, and the substrate acts as a phenomenon of this essence (Grof, 1985; 1993; Sartayeva, 2012; 2018). In this context, the concept of information has a deeper (as opposed to ordinary understanding), "ontological" content, namely—it is the common 
Raushan Sartayeva, Natalya Seytakhmetova, Galiya Kurmangaliyeva, Gulzhikhan Nurysheva, Sholpan Zhandosova

basis that underlies all the phenomena of the world around us.

As to theoretical developments in the field of research of the phenomenon of information, one may note (in line with many researchers) that the underlying concept of information is not clear (Bechmann, 2010). According to Bechmann (2010, p. 114), "the decisive criterion that allows talking about the information society, namely, the information itself, remains unclear in this theory". However, if the phenomenon of information is considered in the context of the holonomicholographic approach, according to which information is the essence of the outside world (that is, it has a deep ontological content), then it is not the information that is "the way and means of transportation of knowledge", as Jürgen Mittelstraß claimed, but vice versa, the knowledge is the way and means of comprehending information as the fundamental essence of reality. But in any case, one can claim that the phenomenon of information (together with the phenomenon of knowledge) is a constitutive feature of the new post-industrial stage in the development of the global megasociety.

Thus, modern scientific research allows considering the phenomenon of information as fundamental in the universe. Nowadays, a dispute between the two greatest modern astrophysicists, Stephen Hawking and Leonard Susskind about whether information disappears in the so-called wormholes (black holes) or not, ended in Susskind's favor after Hawking had officially admitted his defeat at the scientific conference in Dublin in 2004 (Susskind, 2008).

Susskind's conclusions are fundamental and go far beyond astrophysics. According to the recent studies of astrophysicists, the entire universe is filled with information, and the conclusions of Susskind, who is one of the creators of the theory of strings, reveal that information does not disappear anywhere in the universe. According to the string theory, outer space consists of vibrating particles. Moreover, according to Susskind's calculations, it is three-dimensional, and everything that happens in it is reflected in holograms, which are twodimensional and stored in the "film" on the outskirts of the Universe. That is, everything we do, everything we think about, is reflected in the "holograms" in this two-dimensional "film". According to Susskind, it is still unclear why it happens. Susskind's calculations show that this deferred information affects our past, present, and future, which is an even more exciting fact. (Susskind, 2008)

These assumptions are supplemented by the research of the famous American mathematician Benoit Mandelbrot, the British astrophysicist Miles and other concepts and experiments that seem to be extravagant nowadays. 
Certainly, this conclusion is hard to accept from the position of traditional science. But the logic of the development of scientific knowledge is such that the conclusions which seem radical today may become quite acceptable tomorrow (normal, according to Thomas S. Kuhn (1970).

A number of the abovementioned serious modern research works allow us to formulate the following conclusion-information (the thoughts and actions of people creating our reality) that fills the space of the whole universe, does not disappear anywhere and, moreover, shapes our present, future and even affects the past. In this case, the conclusion inevitably follows that information is closely related to the ethical component of the evolution of civilization and is a fundamental category of the latter.

Information, together with knowledge, becomes the most powerful resource in the development of modern society.

According to the authors of this article, it is possible to identify two main modalities of information as a sociocultural phenomenon, although it is necessary to note that this identification is conditional to a certain extent. These are "purely" scientific and geopolitical information resources in the modern informational and communicative space, in which complicated sociocultural processes are occurring today.

One of the features of modern communicative space, formed under the influence of a high level of technological development, which, in its turn, affects the forms and types of social communication, is the construction of virtual reality as a new reality. Some researchers define virtual reality as the "philosophical question of a complex relationship between at least three worlds: the conceivable world, the world visible by a person and the objective world outside of a person" (Menchikov, 1998). In the context of the above definition, virtual reality is secondary to the existential status of a person.

As a result of the transformation of modern culture against the backdrop of globalization, a new spiritual context of society, in other words, a "new spiritual situation" is developing. The spread of new communication technologies has introduced new types of interpersonal relationships and new ways of communication that differ from traditional ones. Thus, the online virtual space as an axiological field of modern information culture no longer involves the establishment of dialogue in its classical sense. 
Raushan Sartayeva, Natalya Seytakhmetova, Galiya Kurmangaliyeva, Gulzhikhan Nurysheva, Sholpan Zhandosova

As noted above, modern research allows considering the phenomenon of information as fundamental in the universe. Information is a basic concept of the so-called holonomic-holographic approach, which was previously described and which is of great importance for modern scientific knowledge, in general. Based on this approach, a new understanding of one of the key principles of philosophy and the whole process of scientific knowledge, that is, the principle of wholeness (the problem of the relationship between the part and the whole), emerges.

A new understanding and methodological content of the principle of wholeness within the framework of the new world outlook, as mentioned above, is that the main thing is not to reveal the internal determination, autonomy of holistic objects and the insufficiency of explaining the characteristics of objects from the outside, but to identify and understand the common origin and the object itself, as well as its "external surroundings". According to the authors of this article, a new understanding of the principle of wholeness is confirmed by the theory of self-organization - that is, synergies. The methodological synthesis of synergetic and sociocultural approaches allows us to consider the human community as a non-equilibrium, non-linear system that develops spontaneously under a bifurcation diagram; and the future of the whole system depends on the behavior of each of us at the bifurcation point.

Moreover, new developments in the field of the theory of consciousness have recently become apparent, and they also indicate that the phenomenon of information is fundamental in our reality. Professor Stuart Hameroff at the Department of Anesthesiology and Psychology of the University of Arizona, and concurrently director of the Center for the Study of Consciousness at the same university, and the famous British physicist and mathematician Roger Penrose developed and advocated the so-called quantum theory of consciousness. According to this theory, the human brain is a quantum computer, consciousness is its software, and the soul is information accumulated at the quantum level. Moreover, this theory indicates that "carriers of consciousness are protein microtubules located inside neurons, which were previously assigned the modest role of "armature" and intracellular transport channels" (see Lagovskiy, 2012). In addition, according to Professor Hameroff, the carriers of quantum information are woven from some material "much more fundamental than neutrons-from the fabric of the universe" (Lagovskiy, 2012).

Besides the "purely scientific" resource of the phenomenon of information (as mentioned previously, such a division is quite conditional), there is also a geopolitical resource. Today, information becomes the most powerful means 
of manipulating public consciousness, together with the internet, which many people, however, perhaps partly rightly, consider as a way to democratize the world. For example, in his book The Third World War is Psychotronic, Etien Kasse (2007, p. 167) wrote: "it is just the right time to rename the media to the mass manipulation media”.

Moreover, information becomes a powerful tool to exert pressure on states. One of the main factors of the development of modern civilization which destroys the sovereignty of nation-states is informational and cultural expansion, used as a tool to exert political pressure. A single global information space is being continuously and purposely created. As many politicians and researchers admit, "information along with finance and intellectual capital becomes the most important resource of political pressure" (Lutsenko, 2006, p. 194). Under the conditions of "transparent borders" created for information flows, these information flows contribute to the expansion of standardized Western cultural values and meanings. Certainly, the leading role is assigned to the internet. By the way, on June 3, 2011, the UN declared the right to free access to the internet as one of the basic human rights.

As already noted, the new 'synthesizing', 'integral', or, as some researchers call it, 'universal' philosophy (Yugai, 2007, p. 15), and new methodological approaches to the study of problems of people are based, among other things, on very interesting, in some cases paradoxical and extraordinary scientific concepts and research. For example, a new scientific direction, developed by Benoit Mandelbrot, the Polish mathematician, who emigrated to the USA. He called this direction 'a chaos theory' and laid out this theory in the book The Fractal Geometry of Nature (Mandelbrot, 1977). Mandelbrot systematized the mysterious phenomena of physics, chemistry, physiology, botany and came to the conclusion that our world has two sides, like any coin. One side, the universal one, is created only by the Absolute Mind, permeating dimensions and space. According to Mandelbrot, the other side of our being is created by the Absolute Mind in cooperation with people, their emotions, imagination, dreams, and intuition. The result is "magic" with an ugly, not always merciful face. According to Mandelbrot, human activity has an impact on reality, on its creation.

This theory of chaos is supported by the theory of dissipative structures by Prigogine and Stengers. According to their theory, any part of such systems which are in a state of bifurcation can affect the next state of this system (Prigogine $\&$ Stengers, 2001). Such theories provide the natural science and methodological rationale for a new understanding of the principle of wholeness. Mandelbrot 
Raushan Sartayeva, Natalya Seytakhmetova,

Galiya Kurmangaliyeva, Gulzhikhan Nurysheva,

Sholpan Zhandosova

theory of chaos (as well as the new understanding of the principle of integrity) is supported by the most interesting, stunning research of the so-called 'psishells', carried out by a group of researchers under the leadership of a British physicist, theorist and experimenter Makhoy Miles (see Pudomyagin, 2007). They started to talk about structures identified as 'souls' and called 'psi-shells' in the early 1970s. It became necessary to answer the most difficult question: whether they contain any useful information and, if so, where this information comes from, how it is processed and used. Through an experiment, Miles' team discovered that each of us was the carrier of six such shells, continuously rejected, penetrating and scanning the universe. These shells carry strictly limited information about all events of our life, our emotions, thoughts, desires, and intentions. (Pudomyagin, 2007)

According to Miles, this process lasts from the moment of a person's birth to death, after which the 'psi-shells' evolve, and the most perfect of them become an integral part "of something super perfect, relatively speaking, divine, the Absolute Mind" (cited in Pudomyagin, 2007). Miles calls this Absolute Mind not only a demiurge, but a flawlessly working "time machine", the "database" of which is filled with inexhaustible information about the events of the past, present, and future. Miles then says that

the experimenters came to the conclusion that all the actions of our contemporaries could influence how the civilization of the Earth would develop in the future. What is overwhelming, but quite acceptable, even on the features of the social system of the distant past. It turns out that our individual mind, interacting with the Absolute Mind, destroys, builds, prophesies. (Cited in Pudomyagin, 2007)

Incredible conclusions! However, Miles and his team are supported by many serious physicists who study the secrets of deep vacuum, high energies, spacetime, multidimensionality, and superconductivities. They support, among other things, the conclusions of Miles' group that the 'psi-shells' of the soul appear to be the deepest known level of matter that is aware of itself. These studies overlapped with the experiments of A. F. Okhtarin (1989) and Roger W. Sperry (2018) on thought forms, from which it is possible to conclude the microlepton nature of thought. This also includes the statement from Agni Yoga that a thought is the subtlest of energies.

The curricula of secondary and higher education systems should include training courses of modern concepts that substantiate the inter-conditionality, 
interdependence of all phenomena of the modern world and spirituality as a practical necessity. This is especially important in our country, which faces the need to solve a big complex of modernization tasks, the fulfillment of which is vital, because today it is about the survival of entire nations in the modern, complex, rapidly changing world.

Production and exploitation of information and knowledge have become the constitutive features of a qualitatively different state of the modern global community (transition to a new level, that is, post-industrial society or information society). The transition of modern society to the information society has caused a number of profound transformations in the cultural domain, which is a dynamically developing informational and communicative space today.

Information, together with knowledge, becomes the most powerful resource in the development of the modern society. Moreover, in the light of the latest scientific research, information is a fundamental category in the context of modern scientific knowledge in general. Information is the basic concept of the so-called holonomic-holographic approach, which is of great importance in the process of modern scientific knowledge in general. Based on this approach, a new understanding of one of the key principles of philosophy and the whole process of scientific knowledge, that is the principle of wholeness (the problem of the relationship between the part and the whole) emerges.

Moreover, in the context of the holonomic-holographic approach, the phenomenon of information is presented as "some initially assigned givenness" (Nalimov, 1989, p. 229), as the fundamental essence of the reality that surrounds us. Therefore, one can claim about the validity of the following statement: it is not information that is "the way and means of comprehending knowledge" (Mittelstraß), but knowledge becomes the way and means of comprehending information as the fundamental essence of the reality that surrounds us.

Modern scientific research provides quite significant arguments in favor of the fact that information about the life of the human community (thoughts, actions, emotions, etc.) can influence not only the present and the future but also the past of the global megasociety. This leads to the conclusion that people should share responsibility for their thoughts and actions since our common future depends on the behavior of each of us. 
Raushan Sartayeva, Natalya Seytakhmetova,

Galiya Kurmangaliyeva, Gulzhikhan Nurysheva,

Sholpan Zhandosova

\section{References}

Abdeev, R. F. (1994), Filosofia informatsionnoi tsivilizatsii [Philosophy of an information civilization. The dialectic of the progressive line of development as a humane universal philosophy for the 21st century], Moscow: Vlados.

Bakaeva, Z. I. (2010), Fenomen informatsii v semanticheskom aspekte [The phenomenon of information in respect of the semantic aspect], $\mathrm{PhD}$ thesis defended at the Chuvash State University named after I. N. Ulyanov, Saransk.

Bechmann, G. (2010), 'Obshchestvo znaniia - kratkii obzor teoreticheskikh poiskov' [The society of knowledge - a brief overview of theoretical inquiry], Voprosy filosofii [Questions of philosophy], no. 2, pp. 113-127.

Bogatyryeva, Y. N. (2000), Fenomen informatsii v kontekste nauchnogo poznaniia: filosofskii analiz [The phenomenon of information in the light of scientific knowledge: philosophical analysis], Candidate of Philosophy thesis, Saratov.

Bohm, D. (1981), Wholeness and the Implicate Order, London: Routledge \& Kegan Paul. https://doi.org/10.1063/1.2914698

Brillouin, L. (1956), Science and Information Theory, New York: Academic Press.

Chew, G. F. (1968), “'Bootstrap”: a scientific idea?' Science, vol. 161, no. 3843, pp. 762-765. https://doi.org/10.1126/science.161.3843.762

Davidovich, V. Y. (1997), Zerkalo filosofi [In the mirror of philosophy], Rostov-onDon: Feniks.

Drucker, P. F. (1969), 'Knowledge society,' New Society, vol. 13, no. 343, pp. 629-631.

Garai, L. (2010), 'Diada Vygotskogo i chetveriada Rubinshteina (interviu s professorom Laslo Garai)' [Vygotsky's Dyad and Rubinstein's Tetrad (An interview with Professor Garai)], Voprosy filosofi, vol. 12, pp. 36-43.

Garai, L. (2017), Reconsidering Identity Economics: Human Well-Being and Governance, New York: Palgrave Macmillan. https://doi.org/10.1057/978-1-137-52561-1

Garai, L. (2019), 'The complimentary of the information theory and the identity theory in human sciences,' Voprosy Filosofi, vol. 5, pp. 118-123.

https://doi.org/10.31857/S004287440005061-2

Grof, S. (1985), Beyond the Brain: Birth, Death, and Transcendence in Psychotherapy, New York: State University of New York Press.

Grof, S. (1993), Za predelami mozga. Rozhdenie, smert' i transtsendentsiia v psikhoterapii [Beyond the brain: birth, death, and transcendence in psychotherapy], transl. from English by A. Kiselev, Moscow: AST.

Hartley, R. (1959), 'Information transmission,' in A. A. Kharkevich (ed.) Information Theory and Its Applications, Moscow: Fizmathlit, pp. 5-35.

Hintikka, J. (2011), 'Filosofskie issledovaniia: problemy i perspektivy' [Philosophical research: problems and prospects], Voprosy filosofii, vol. 7, pp. 3-18. 
Ingwersen, P. (1992), 'Information and information science in context,' II Libri Copenhagen, vol. 42, no. 2, pp. 99-135. https://doi.org/10.1515/libr.1992.42.2.99

Kasse, E. (2007), Tretia mirovaia psikhotronnaia voina ona uzhe nachalas [The third world war is psychotronic], St. Petersburg: Nevskiy Prospect \& Vector.

Kasumova, G. K. (2011), 'Sotsiokulturnaia realnost globaliziruiushchegosia mira' [The sociocultural reality of the globalizing world], Vestnik Moskovskogo Universiteta [Bulletin of Moscow University], Series 7. Philosophy, no. 3, pp. 87-98.

Kochetkov, A. P. (2011), 'Vlast i elity v global'nom informatsionnom obshchestve' [Power and elite in the global information society], Polis, no. 5, pp. 8-20.

Kuhn, T. S. (1970), The Structure of Scientific Revolutions, 2nd ed., Chicago: University of Chicago Press.

Lagovskiy, V. (2012), 'Finally, the place where people have a soul has been found,' Komsomolskaia Pravda, 13 November, no. 170 (25983), p.15.

Letov, O. V. (2009), 'Eticheskie i filosofskie aspekty nanotekhnologii. (Svodnyi referat)' [Ethical and philosophical aspects of nanotechnology. (Summary)], RZh, no. 3, pp. 82-112.

Lutsenko, K. (2006), 'Kto pobedit? Natsionalnoe gosudarstvo v epokhu globalizatsii' [Who will win? Nation-state in the era of globalization], Svobodnaia mysl [Free thought], no. 3, pp. 192-199.

Machlup, F. (1979), 'Stocks and flows of knowledge', Kyklos, vol. 32, nos. 1-2, pp. 400-411. https://doi.org/10.1111/j.1467-6435.1979.tb02614.x

Mandelbrot, B. (1977), The Fractal Geometry of Nature, San Francisco: Freeman.

Masuda, Y. (1981), The Information Society as a Post-industrial Society, Bethesda, MD: World Future Society.

Menchikov, G. P. (1998), Virtual'naia real'nost': poniatie, novatsii, primenenie [Virtual reality: concept, innovation, application], Filosofskie nauki, no. 3-4, pp. 170-175.

Nalimov, V. V. (1989), Spontannost soznaniia: Veroiatnostnaia teoriia smyslov $i$ smyslovaia arkhitektonika lichnosti [Spontaneity of consciousness. A probabilistic theory of meanings and semantic architectonics of personality], Moscow: Prometheus.

Okhtarin, A. (1989), Macroclusters and Ultralight Particles, Reports of the Academy of Sciences of the USSR, vol. 304, no. 4, pp. 866-869.

Prigogine, I. \& Stengers, I. (2001), Vremia, khaos, kvant: $k$ resheniu paradoksa [Time, chaos, quantum. To the solution of the paradox of time], 3rd ed., Moscow: Editorial URSS.

Pudomyagin, A. (2007), 'Pravilnyi kotel dushi' [The melting pot of the soul], NLO, no. 5, pp. $12-13$.

Sperry, R. W. (2018), Nobel Lecture: Some Effects of Disconnecting the Cerebral Hemispheres, Nobelprize.org, Nobel Media AB, 9 August.

Sartayeva, R. S. (2012), Ekologiia cheloveka, novaia ontologiia i ustoichivoe razvitie Kazakhstana [Human ecology, new ontology and sustainable development of 
Raushan Sartayeva, Natalya Seytakhmetova,

Galiya Kurmangaliyeva, Gulzhikhan Nurysheva,

Sholpan Zhandosova

Kazakhstan], Almaty: Institute for Philosophy, Political Sciences and Religion Studies of the Committee of Science of the Ministry of Education and Science of the Republic of Kazakhstan.

Sartayeva, R. S. (2018), Ekologiia cheloveka, novaia ontologiia $i$ ustoichivoe razvitie Kazakhstana [Human ecology, new ontology and sustainable development of Kazakhstan], Monograph / Under the general editorship of A. Kh. Bizhanova, 2nd revised edition, Almaty: Institute for Philosophy, Political Sciences and Religion Studies of Committee Science of the Ministry of Education and Science of the Republic of Kazakhstan.

Shannon, C. E. (1948), 'A mathematical theory of communication,' reprinted with corrections from The Bell System Technical Journal, vol. 27, pp. 379-423, 623-656. https://doi.org/10.1002/j.1538-7305.1948.tb00917.x

Shannon, K. (1963), Raboty po teorii informatsii $i$ kibernetike [Papers on the theory of information and cybernetics], Moscow: Izd-tvo inostrannoi literatury.

Smolyan, G. L. (2001), 'Informacii teoria' [Information theory], in Novaia filosofskaia entsiklopediia [New philosophical encyclopedia], vol. 2 'E-M', Moscow: Mysl, pp. 141-142.

Solovyev, Y. G. (2001), 'Informatsionnoe obshchestvo' [Information society] in Novaia filosofskaia entsiklopedia [New philosophical encyclopedia], vol. 2 'E-M', Moscow: Mysl, p. 142.

Susskind, L. (2008), The Black Hole War: My Battle with Stephen Hawking to Make the World Safe for Quantum Mechanics, New York: Little, Brown \& Company.

Ursul, A. D. (1983), 'Informatsiia,' [Information] Filosofskii entsiklopedicheskii slovar [Philosophical encyclopaedical dictionary], Moscow: Soviet Encyclopedia, pp. 217218.

Wiener, N. (1948), Cybernetics, or Control and Communication in the Animal and the Machine, Cambridge, MA: MIT Press.

Young, A. M. (1976), The Geometry of Meaning, New York: Delacorte Press.

Yugai, G. A. (2007), Golografiia vselennoi. Novaia universalnaia filosofiia. Vozrozhdenie metafiziki $i$ revoliutsiia $v$ filosofi [The holography of the Universe and the new universal philosophy. The revival of metaphysics and the revolution in philosophy], Moscow: CRAFT.

\section{Raushan Sartayeva Natalya Seytakhmetova Galiya Kurmangaliyeva}

Institute for Philosophy, Political Sciences and Religion Studies of the Committee of Science of the Ministry of Education and Science of the Republic of Kazakhstan 


\section{Gulzhikhan Nurysheva}

Philosophy Department, Al-Farabi Kazakh National University

\section{Sholpan Zhandosova}

Department of Religious Studies, Institute for Philosophy, Political Sciences and Religion Studies of the Committee of Science of the Ministry of Education and Science of the Republic of Kazakhstan 